(Stockholm), read by H. Burnham (Royal Ontario Museum), Dr. J. E. Leene (Laboratory for Textile Technology, Delft), Miss L. Bellinger (Textile Museum, Washington) and E. R. Beccher (Victoria ond Albert Museum, London).

The final session was on the subject of the education and training of conservators and restorers, perhaps the most important of all since, in the absence of proper training, standards cannot be maintained. Speakers were: Prof. P. Rotondi, the now head of the Istituto Contrale del Restauro, Rome; S. Keck, the now director of the New York University Conservation Center; H. Ruhemann (London), Prof. B. Marconi (Academy of Fine Arts, Warsaw) and H. W. M. Hodges (Institute of Archæology, London). There was unfortunately very little time for discussion.

Insufficient time for discussion was in fact tho major complaint of the delegates and was foreseon by the organizers. Only a limited time was available, and a huge range of subjects had to be represented. Future conferences will deal with certain of these subjects separately.
(XARRY THOMSON

\title{
ANIMAL COMMUNICATION AND LEARNING PROCESSES
}

$\mathrm{T}$

HE eighth of a sories of symposia organized by the Zoological Society of London was held during November 8-9 jointly with the Association for the Study of Animal Behaviour. The first day was devoted to a discussion of "Evolutionary Aspects of Animal Communication", and the socond to a discussion of "Imprinting and Early Learning".

Dr. N. Tinbergen (Oxford) oponod the fixst day's procerdings with a eritical oxamination of mothods or, as he put it, with 'soul-searching' concorning the validity of evidence derived from the study of present communication patterns for the making of generalizations about their evolutionary history and taxonomic relevance in the absence of 'fossil' evidence. Often the assessment of sequences proves difficult, and it is frequently hard to pin-poirit the solection valuo of deviations from the norm. The question was discussed whother the manifest act of communica. tion or its underlying neuromuscular pattern is the substrate for solection.

In a paper on the "Snapping Movement of the Blue Heron" Dr. G. P. Buerends (Groningen) submitted that the 'snap display' of this bird did not, as had been thought, originate as a displacoment activity from fish-soizing or nost-building but was primarily caused by an interaction of tendencios to attack and oscape and is thus a typically ambivalont movemont. The wing display of tho junglo fowl during waltzing was doscribed by J. P. Kruijt (Groningen) as a compromise between simultaneously activated motor patterns.

Prof. D. S. Lehrman, Rutgers University, analysed the part played by endocrine responses to sensory stimulation from follow-members of a species and omphasized the great importance of hormonal stimulusresponse relationships in the communication of physiological states. In a paper on the evolutionary aspects of courtship songs in the estrildine finches, Dr. Fae Hall (London) demonstrated that the song of these birds has no proved territorial or hostilo function, but is primarily a r tualized sexual signal immediately preceding copulation. The various songs appear to bo species-specific and act as sexual isolating mechanisms. Dr. J. H. Crook (Cambridgo) showed how in plocerine weaver birds the various combinations of six basic behaviour patterns aro associatod with habitat and solitary or gregarious habit. Or. M. R. A. Chance (Birmingham) diseussed the significance of agonistic postures and devoloped a hypothesis that they serve as cut.off onabling aversive drives to wane and social intercourse to continue.

Vocal communication patterns in Rhosus monkoys were demonstrated by Dr. 'Thelma Rowell (Cambridge), who pointed out that a set number of noises with their various intermediates can be identified, but prove to be closely associated with certain postures and movements. They cax therofore not be studiod in isolation, but only in conjunction with tho activity of the animal as a whole. Facial oxpressions in primates were discussed by J. van Hoff (Utrecht), who dirocted attention to the fact that only the higher primates, the highor carnivores and the ungulates have developed an elaborate system of social signels concentratod in the facial region, and that this sooms to be correlatod with tho specializations of the sense of vision. Various compound oxprossions each result from balance of aggression and fear.

Tho second day of tho symposium openod with loctures by Dr. TR. $\Lambda$. Hinde (Cambridgo) and Dr. E. Fabricius (Stockholm), who, each in his own way, challongod the critoria set out originally by Konrad Loronz as distinctive for this kind of learning. Thus it was argued that tho absenco of reward, the existence of a critical period, the rupidity of the process, its irroversibility, its supra-individual significance, the particular absence of any innate releasing mochanism, the question of regulative or mosaic determination, and finally tho relationship between imprinting and soxual orientation to the foster paront have all beon conclusivoly challonged by observation and experimont. Dr. Hinde pointod out that, although imprinting is not a uniquo form of learning, it poses many problems with wide ramifications and provides a context in which thoy can be studied in dotail.

In a paper on early learning in Sepia, M. J. Wolls (Cambridgo) showed how newly hatched animals are dominated by innate mechanisms for attack of cortain food organisms, but how later on an ever-widening range of objects elicit attack. During the first month aftor hatching thore is very little evidence of learning, but by the middle of the second month, that is, procisely when the vertical lobe of the brain becomos fully developed, the animals loarn to deal with more varied proy.

Prof, F. V. Smith (Durham) discussed certain perceptual aspects of imprinting, and described three groups of experimonts in which the perceptual factors in initial approach, tho duration of responses and relative strength of stimuli, and the hypothesis of effort (E. H. Hess) wore examined. Dr. W. Sluckin (Loicester) discussod the relationship botween perceptual and associativo learning and pointed to some important difforences betweon them. The capacity for percoptual learning remains steady for some time, but declines with age, whereas associative learning improves with age for a long time.

I)r. E. A. Salzen (Liverpool) analysed the relationships between "Imprinting and F'ear". Ho suggested 
that persistent patterns of sonsation give rise to 'models' of static and dynamic environments the disruption of which by unfamiliar stimulus patterns releases emotional behaviour in the form of fear responses. J. P. Kruijt, in a second contribution to the symposium, spoke on imprinting in relation to drive interactions in Burmese red jungle fowl, and showed that the ability to integrate attack and escapo into ambivalent behaviour is an important factor in the performance of successful copulatory behaviour. Dr. P. E. Guiton (Edinburgh) gave a domonstration of the development of sexual responses in the domestic fowl in relation to the concept of imprinting. $\mathrm{He}$ claimed that sexual attachments may he formed as a consequence of the parent-young bond apparently before overt sexual behaviour is normally possible. Persistent sexual attachments to human beings can be induced in domestic cocks by early social contact with man. There is evidence that endogenous androgens are secreted by chicks.

The symposium was wound up by a discussion on some of the controversial aspects of imprinting initiated by Dr. W. H. Thorpe (Cambridge). Both sessions excelled by the quality of the papers and illustrations by slides and film, and thore were some most useful and informative discussions in those instances when speakers allowed sufficient time for them. O. E. Lowenstern

\section{GEOPHYSICAL MEASUREMENTS IN THE UPPER ATMOSPHERE}

A GEOPHYSICAL discussion on the subject of the upper atmosphere was held at the Royal Astronomical Society, London, on November 24, with Mr. J. A. Ratcliffe, director of the Radio Research Station, Slough, as chairman.

There were four main speakers. The first, D. G. King-Hele (Royal Aircraft Establishment, Farnborough), discussed atmospheric density and its varietions at heights of $180-700 \mathrm{~km}$., as revealed by the changes in satellite orbits. The air drag acting on a satellite near its perigee point causes its orbit to contract, and by measuring the rate of contraction the air density near perigee can be deduced. The results obtained by this method have been very consistent and satisfactory, and have shown that the density tends to fluctuato in response to solar activity, the density being greatest when the Sun is most active. At heights abovo $300 \mathrm{~km}$. there is also a large variation between day and night, the maximum day-time density exceeding the minimum night-time density by factors of $2 \frac{1}{2}$ at $400 \mathrm{~km}$. and 8 at $600 \mathrm{~km}$.

The second speaker was H. Rishbeth (Redio Resoarch Station, Slough), whose subject was "Atmospheric Composition and the $F$-layer of the Ionosphere". The electron distribution in the upper atmosphere is controlled by photochomical processes -the production and loss of ionization-which are dominant in the $E$ - and $F$-layers, and by movements, such as electromagnetic drift and diffusion, which are important in the $F_{2}$-layer. Dr. Rishbeth also discussed the seasonal anomalies in the $F$-region: the peak electron density is much greater in winter than in summer; the electron density near the $F_{2}$. peak increases at sunrise more rapidly in winter; and the midnight electron density is greater in summer than in winter. Finally, he touched on the effect of magnetic storms.

The third speaker was $\mathrm{K}$. Woekes (University of Exeter), who discussed the results obtained from the distribution of ionization above the maximum of the $F$-region. This ionization can be derived by three methods: $(a)$ study of tho Doppler effect and Faraday rotation on the radio signals emitted by satellites; (b) incoherent scattering by free electrons; (c) the Faraday method applied to Moon echoes. Method (a) gives the scale-height of positive ions as about $60 \mathrm{~km}$. at heights of $300-600 \mathrm{~km}$. Method $(b)$ has given scale-he ghts of $55 \mathrm{~km}$. at $400 \mathrm{~km}$. rising to $90 \mathrm{~km}$. at $700 \mathrm{~km}$. height, corresponding to tempera tures of $900-1,500^{\circ} \mathrm{K}$. There is, however, no indica- tion as yet from these results of the change in temperature between day and night suggested by the changes in density revealed by satellite orbits.

The fourth speaker was R. L. F. Boyd (University College, London), who described the measurement of electron temperature by means of Langmuir probes on rockets or satellites. The electrode is negatively biased, and the current flowing depends on the ability of the electrons to surmount this bias. The method has three advantages: it gives instantaneous values, can detect differences between electrons and neutral particles, and measures temperature directly. Dr. Boyd then gave some recent results obtained from a firing of a Black Knight rocket to a hoight of moro than $500 \mathrm{~km}$., at a time $2 \frac{1}{2} \mathrm{hr}$. after sunset. The temperatures obtained increased from about $1,000^{\circ} \mathrm{K}$. at $300 \mathrm{~km}$. to nearly $2,000^{\circ} \mathrm{K}$. at heights of $500-600$ $\mathrm{km}$. At the lower altitudes, these values agree with the night-time values deduced from the analysis of satellite orbits, but at the higher altitudes they are nearer the day-time values, suggesting possibly that the decrease in temperature after sunset is not so rapid at these heights.

In the subsequent discussion, G. V. Groves (University College, London) commented on the rather puzzling fact that changes in air density revealed by satellite orbits at the time of the great magnotic storm in November 1960 seemed to be almost independent of latitude and longitude, whereas one might have expocted the effects due to particles from the Sun would be stronger near the poles. Mr. Ratcliffe suggested that if the heating were due to hydromagnetic waves, the fairly uniform distribution would be more intelligible.

J. M. Stagg (Royal Meteorological Society) referred to the existence of another variation in air density at heights above $200 \mathrm{~km}$., namely, an annual variation with a minimum in June and a rather flat maximum in October-December, and other speakers mentioned somewhat similar effects in the ionosphere.

After considerable further discussion, on topics which included upper-atmosphere winds, the intermediate ' $F_{11}$ ' peak in electron density and changes in atmospheric composition, $\mathrm{Mr}$. Ratcliffe summed up. The meeting had been a fruitful one, he thought, and particularly because it had brought together three groups: those who are working with rockets and satellites, the ionospheric physicists, and the meteorologists. He thanked the Royal Meteorological Society for sending a strong delegation, which contributed much to the discussion. D. G. KuNG-Hele 